\title{
Laboratory comparative assessment of warm and hot mixes Asphalt containing reclaimed Asphalt pavement
}

\author{
Hasan $\mathrm{H}$ Joni ${ }^{1} \mid$ Aqeel Y M Alkhafaji ${ }^{2}$ |
}

\begin{abstract}
Affiliations
${ }^{1}$ Civil Engineering Department, University of Technology, Baghdad, Iraq

${ }^{2}$ State of roads and bridges, Babylon Governorate, Babylon, Iraq

\section{Correspondence}

Aqeel Y M Alkhafaji,

${ }^{2}$ State of roads and bridges, Babylon Governorate, Babylon, Iraq

Email:

42372@student.uotechnology.e du.iq

Received

04-October-2020

Revised

04-November-2020

Accepted

09-November-2020

Doi:10.31185/ejuow.Vol8.Iss2.164
\end{abstract}

\begin{abstract}
Warm mix Asphalt (WMA) could be mixed and used in paving at low temperatures to minimize the consumption of energy and the emissions of greenhouse gas. Recycled Asphalt pavement (RAP) could save Asphaltic cement and aggregate, which could achieve the better effects of recycling. However, both of the two WMA and RAP technologies have some deficiencies. Warm mix Asphalt and Reclaimed Asphalt pavement (WMARAP) technique may solve these issues and deficiencies when they are utilized together. This study investigated the implementations of WMA-RAP and its impacts on the performance of the Asphalt mixture. Under the framework of this study, four percentages of RAP $(0 \%, 20 \%, 30 \%$, and $40 \%)$ were added to the hot mix Asphalt (HMA) and WMA containing 4\% Sasobit to study the impact of increasing RAP content on Marshall stability and moisture resistance of Asphalt mixtures. In summary, the Marshall stability of HMA and WMA mixtures is higher than the control mixtures. A small decrease in moisture resistance of both (HMA and WMA) containing RAP comparing to control mixtures Asphalt was observed, as shown by reduced the tensile strength ratios (TSR), but it is still much higher than the minimum of $80 \%$.
\end{abstract}

Keywords: HMA, moisture damage, RAP, Sasobit; WMA.

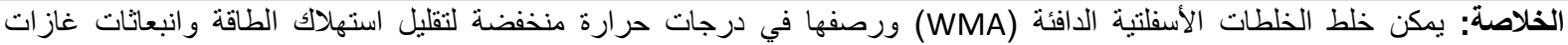

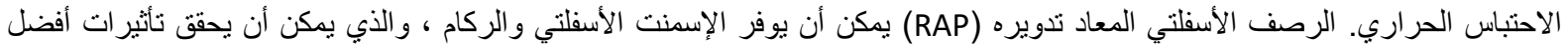

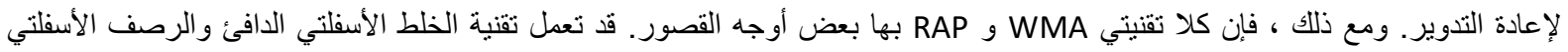

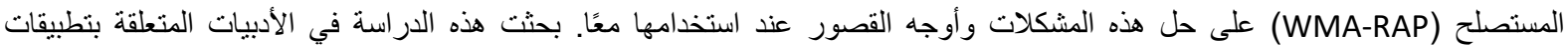
وتأثير ها على أداء الخليط الأسفلتي. في إطار هذه الدراسة ، تمت إضافة أربعة نسب (·WA (WMA-RAP)

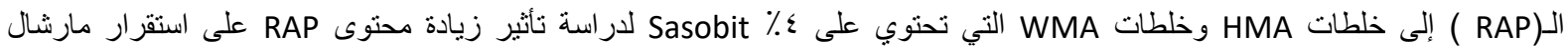

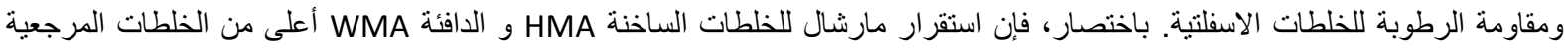

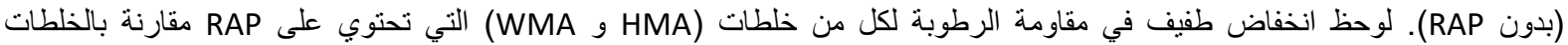

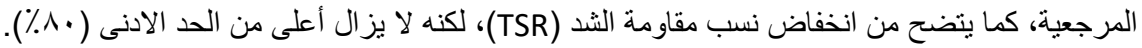

\section{INTRODUCTION}

The Asphalt industry has studied the warm Asphalt technology in recent years as a way of minimizing production and placement temperature in Asphaltic mixes. The WMA was an Asphalt mixture that is produced at a lower temperature in comparison to traditional hot mix Asphalt (HMA) mixture. In addition to reducing consumption of energy, carbon dioxide emissions and Asphalt deterioration, WMA technology extends the paving season and improves paving length for a safer working climate. Reducing the energy consumption helps in reducing project costs as a direct consequence of reducing the temperature of WMA manufacture [1-5]. Reductions in energy consumption ranged from $10.0 \%$ to $30.0 \%$ on average when the temperature of heating dropped of $150^{\circ} \mathrm{C}$ to about $125^{\circ} \mathrm{C}[6,7]$. 
Recently, the cost of HMA has substantially increased, largely due to the rise in the price of the Asphalt binder. Users are seeking ways to minimize the costs of the Asphalt mixtures so that pavements can be properly maintained and rehabilitated with the available funds. One of the most successful ways to reduce the cost of Asphalt construction is to use more Recycled Asphalt Pavement (RAP) in mixtures. The identities for the maximum quantity of RAP to be utilized in HMA have been identified in several states, mainly due to fears about unwanted substantial properties of RAP such as an aged binder, low quality of aggregates, and lack of effective mix design method for HMA mixtures with high contents of RAP [8].

There is an urgent requirement for more research to assess ways of using higher contents of RAP while guaranteeing continued best performance. The use of WMA technology with mixtures containing high RAP content was of great importance because this combination has the potential to minimize the cost of the mixture, to minimize the gases emissions, to improve the performance of mixture, to minimize the fuel amount used during the production and placement operations, and to reduce the requirements of virgin Asphalt and aggregates. The technology of WMA mixture has been shown to improve the workability of mixture, to minimize the Asphalt binder aging during construction, to get a better density in-place, and to helping to ensure that no occur any emissions of gases. The potential that WMA technology and high contents of RAP can be used simultaneously is very encouraging [8]. The use of reclaimed Asphalt pavement has several advantages, especially economic and environmental, particularly associated to the lowering consumption of aggregates and binders (which have lately suffered significant price increases) and the reduction of haul-distances, thus producing less environmental impacts [9].

A study was conducted on rubberized Asphalt mixes containing 4\% and 5.5\% Sasobit with 30\% and 60\% RAP. These mixes containing high RAP and high Sasobit indicated to provide good behavior to resist moisture damage in compared with the traditional mixture, $\mathrm{CW}$ [10]. A present study evaluated moisture performance of hot mixture Asphaltic (HMA) and 2\% warm mixture Asphaltic (WMA). Both mixes (HMA and WMA) containing $(0 \%, 10 \%, 20 \%, 30 \%$, and $40 \%)$ of RAP materials. The outcomes exhibited that the TSR value of the HMA with RAP was higher than that of the WMA with RAP for all RAP contents, showing that WMA mixes are more susceptible to moisture damage comparison to HMA mixes[11]. Another study has investigated the impact of Zycotherm and Sasobit on the characteristics of WMA containing RAP. Moisture sensitivity was assessed by applying the tensile strength ratio, resilient modulus ratio, and fracture energy ratio. The finding of laboratory testing exhibited that the WMA containing Zycotherm had less susceptible to moisture damage than the WMA containing Sasobit and HMA mixtures. The increase of mixes stiffness by raising the content of RAP and utilizing Sasobit aggravated this issue [12].

A researcher has investigated the impacts of WMA containing $1.5 \%$ Sasobit with $(30 \%, 40 \%$, and $50 \%)$ of RAP in the laboratory. The performance of the mixes in terms of stiffness and moisture damage was investigated by carrying out the Indirect Tensile Resilient Modulus Test (ASTM D4123) and moisture susceptibility test (ASTM D4867). The outcomes exhibited that there were not substantially variations in volumetric characteristics, stability, and stiffness values of reclaimed mixes than the control mix (conventional hot mix Asphalt). In addition, all the mixes investigated achieved the required minimum TSR of $80 \%$. The results showed that WMA using Sasobit-additive and containing high percentages of RAP could be a sustainable alternative to the conventional HMA mix [13]. Another researcher assessed the moisture sensitivity of WMA containing high RAP content by TSR and MR tests. The amount of RAP had an important impact on moisture sensitivity as the results of TSR and MR tests exhibited that the WMA with 30 percent RAP had a better impact on moisture sensitivity, and the RAP adding more than 30 percent may have a negative action [14].

\section{RESEARCH OBJECTIVE}

This research aims to assess the impact of reclaimed Asphalt pavement (RAP) in different percentages on Marshall stability and moisture resistance of hot and warm Asphalt mixtures, by determining the Marshall stability and flow value, while strength and stiffness of mixtures through IDT test for conditioned and unconditioned samples.

\section{MATERIALS}

\subsection{Asphalt Cement}

The virgin Asphaltic cement chosen for this investigative process with a penetration grade of (40/50) was obtained from the Refinery of AL-Daurah base bitumen (AC 40/50). Table 1 exhibited the physical characteristics of the Asphalt cement according to (ASTM Standard Designation). 
Table 1. Physical characteristics of Asphalt binder and standards limitations.

\begin{tabular}{|l|c|c|c|}
\hline \multicolumn{1}{|c|}{ Tests } & Standard & Tests value & $\begin{array}{c}\text { Standards Limitations as per to } \\
\text { SCRB / R9, 2003 }\end{array}$ \\
\hline Penetration, $25{ }^{\circ} \mathrm{C},(0.1 \mathrm{~mm})$. & ASTM. D.5 & 48 & $40-50$ \\
\hline Ductility, $25^{\circ} \mathrm{C}, 5 \mathrm{~cm} . / \mathrm{min}$. & ASTM. D.113 & +140 & $>100$ \\
\hline Softening Point, $\left({ }^{\circ} \mathrm{C}\right)$ & ASTM. D.36 & 51.5 & ---- \\
\hline Specific gravity, $25^{\circ} \mathrm{C}$ & ASTM. D.70 & 1.045 & ---- \\
\hline Flash \& fire points & ASTM D.92 & $295^{\circ} \mathrm{C} \mathrm{\&} 302^{\circ} \mathrm{C}$ & $>232^{\circ} \mathrm{C}$ \\
\hline Rotational Viscosity ${ }^{\text {a }}$ & ASTM. D.4402 & $543 @ 135^{\circ} \mathrm{C}$ & \\
(centistokes) & & $157 @ 165^{\circ} \mathrm{C}$ & \\
\hline
\end{tabular}

a The test was done in Asphalt Laboratory of Civil Engineering Department, University of Karbala.

\subsection{Aggregates and Mix Type}

The used aggregates for this work have been selected from Quarry of al-Nibaie, which was widely used in the production of Asphalt mixture. Laboratory experiments were used to quantify the chemical and physical characteristics according to (ASTM Standard Designation) for coarse and fine aggregate as exhibited in Tables 2 and 3 , respectively.

Table 2. Laboratory results from physical properties of the coarse aggregates.

\begin{tabular}{|c|c|c|c|}
\hline Test in laboratory & ASTM Designation & Results & Specification \\
\hline Apparent Specific gravity & \multirow{3}{*}{ ASTM C127 } & 2.661 & \multirow[t]{3}{*}{-----} \\
\hline Bulk Specific gravity & & 2.625 & \\
\hline Absorption, \% & & 0.362 & \\
\hline Angularity & ASTM D 5821 & $97 \%$ & Min. 95\% \\
\hline Soundness & ASTM C88 & 4.1 & Max. $12 \%$ \\
\hline Flat & \multirow{2}{*}{ ASTM D4791 } & $1.1 \%$ & \multirow[t]{2}{*}{ Max. $10 \%$} \\
\hline Elongation & & $2.8 \%$ & \\
\hline $\begin{array}{l}\text { Toughness, } \\
\text { by (Los Angeles Abrasion) }\end{array}$ & ASTM C535 & $20.8 \%$ & Max. $30 \%$ \\
\hline
\end{tabular}

Table 3. Laboratory results from physical characteristics of the fine aggregate.

\begin{tabular}{|c|c|c|c|}
\hline Test in laboratory & ASTM & Test result & Specifications \\
\hline Specific gravity (Apparent) & \multirow{3}{*}{ ASTM C128 } & 2.642 & \multirow[t]{3}{*}{ Specimications } \\
\hline Bulk Specific gravity & & 2.615 & \\
\hline Absorption, \% & & 0.480 & \\
\hline Equivalent sand (clay content) & ASTM D2419 & $86.5 \%$ & Min. $45 \%$ \\
\hline
\end{tabular}

The nominal maximum size of the aggregate chosen for the aggregate gradation-used in Asphalt concrete mix for the trail specimens for wearing course-was $12.5 \mathrm{~mm}$ according to the Iraqi State Corporation for Roads and Bridges SCRB [15], as illustrated in Table 4.

Table 4. Gradation of Asphalt Mix.

\begin{tabular}{|l|c|c|c|c|c|}
\hline \multicolumn{2}{|c|}{ Sieve Size } & \multicolumn{1}{c}{$\begin{array}{c}\text { 2003) wearing course type IIIA } \\
\text { 203sing Iraqi Specifications (S.C.R.B R/9, }\end{array}$} \\
\hline Standard Sieves & English Sieves & Min. & Max. & \% Passing & \% Retaining \\
\hline $19.00 \mathrm{~mm}$ & $3 / 4 "$ & --- & 100 & 100 & 0 \\
\hline $12.50 \mathrm{~mm}$ & $1 / 2 "$ & 90 & 100 & 95 & 5 \\
\hline $9.50 \mathrm{~mm}$ & $3 / 8 "$ & 76 & 90 & 83 & 12 \\
\hline $4.75 \mathrm{~mm}$ & $\# 4$ & 44 & 74 & 59 & 24 \\
\hline $2.36 \mathrm{~mm}$ & $\# 8$ & 28 & 58 & 43 & 16 \\
\hline $0.30 \mathrm{~mm}$ & $\# 50$ & 5 & 21 & 7 & 30 \\
\hline $0.075 \mathrm{~mm}$ & $\# 200$ & 4 & 10 & & 6 \\
\hline Pan & --- & & & & 7 \\
\hline
\end{tabular}

The type of Asphalt mixture was dense graded and the optimum Asphalt cement content is found based on Marshall mix design method ASTM D 6926-10 [16] and ASTM D6927-15 [17]. 


\subsection{Warm Mix Additive}

The modifier additive included in this work is Sasobit as shown in Figure 1, which is extracted from the process of gasification of coal. It is manufactured by the company of Sasol Wax. The chemical composition of Sasobit consists of fine crystalline in a long chain-hydrocarbon, production by different ways of synthesis of Fischertropsch (F-T). The melting point of the Sasobit additive, as mentioned by the producer, is about $100{ }^{\circ} \mathrm{C}$ to 105 ${ }^{\circ} \mathrm{C}$ and it was completely dissolved in bitumen at a temperature over $115^{\circ} \mathrm{C}$ [18]. Table 5 shows the rheological characteristics of Sasobit.

Table 5. Rheological characteristics of Sasobit [18].

\begin{tabular}{|c|c|c|c|c|c|}
\hline Parameters & $\begin{array}{l}\text { Congealing } \\
\text { Point, }{ }^{\circ} \mathbf{C}\end{array}$ & $\begin{array}{l}\text { Penetration } \\
\text { at } \mathbf{2 5}{ }^{\circ} \mathbf{C}\end{array}$ & $\begin{array}{l}\text { Penetration } \\
\text { at } \mathbf{6 5}{ }^{\circ} \mathbf{C}\end{array}$ & $\begin{array}{l}\text { Laboratory } \\
\text { Melting, }{ }^{\circ} \mathbf{C}\end{array}$ & $\begin{array}{l}\text { Brookfield Viscosity } \\
\text { at } \mathbf{1 3 5}\end{array}$ \\
\hline Max & 100 & 0 & 0 & 75 & 10 \\
\hline Min & 110 & 2 & 13 & 115 & 15 \\
\hline
\end{tabular}

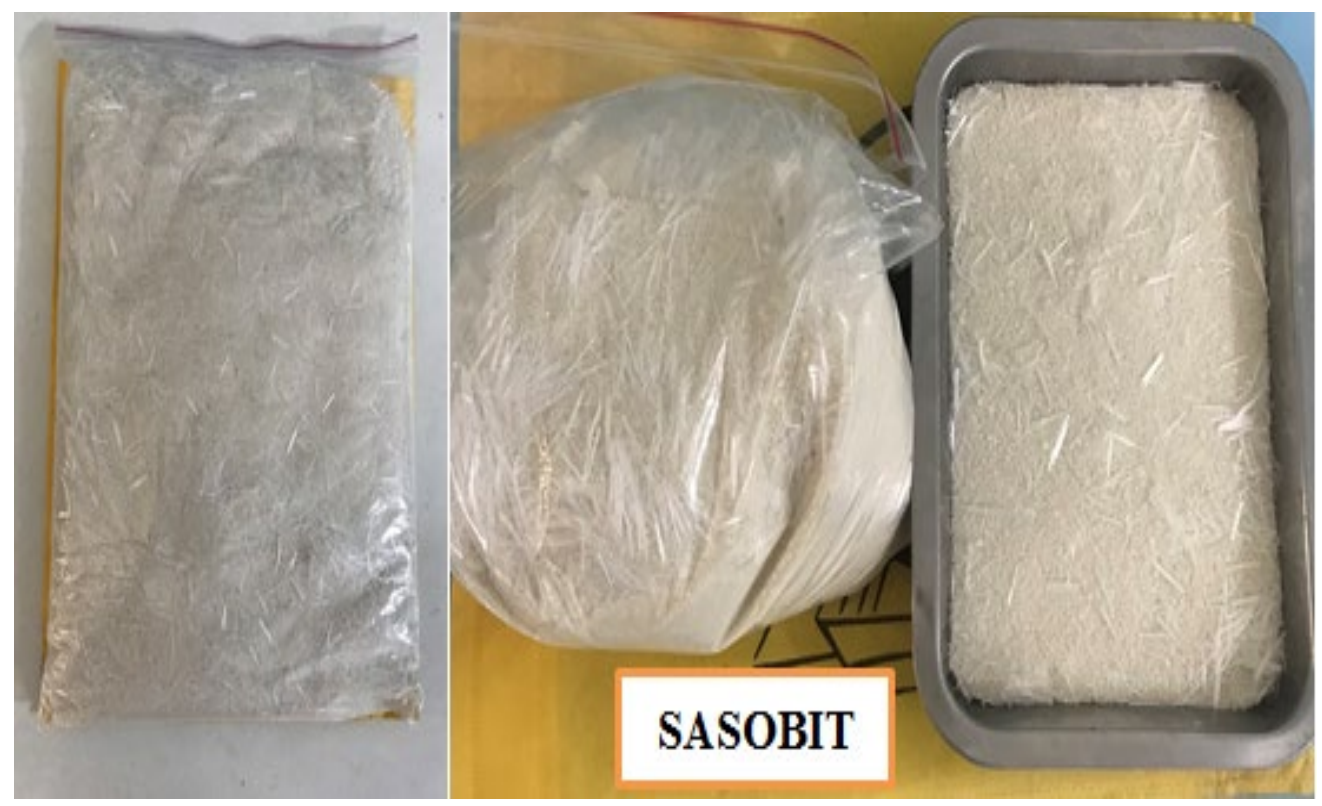

Figure 1. Sasobit organic additive material.

\subsection{Modified Asphalt Binder}

Sasobit is used in $4 \%$ to be mixed with pure Asphalt binder (40/50 penetration) to produce the modified Asphalt binder used in the production of the WMA. For Sasobit to be thoroughly mixed with the Asphalt, the Asphalt cement must be heated between $130{ }^{\circ} \mathrm{C}-140^{\circ} \mathrm{C}$. Then the Sasobit was added and mixed using a fan mixer to obtain a modified WMA-Sasobit.

\subsection{Reclaimed Asphalt Pavement}

The recycled Asphaltic pavement (RAP) used in all mixtures in this research was obtained from surface milling of Hilla - Baghdad Highway in Hilla city in Iraq and tested to determine the percentage of Asphalt binder content according to ASTM D6307 - 10 "Asphalt content by Ignition Furnace" [19], which is shown the average Asphalt content of RAP was 4.7\%. This RAP was tested for the particle size distribution as illustrated in Table 6. 
Table 6. Reclaimed Asphalt pavement (RAP) material gradation.

\begin{tabular}{|l|c|c|c|c|c|}
\hline \multicolumn{2}{|c|}{ Sieve Size } & $\begin{array}{c}\text { \% Passing by (S.C.R.B. R/9, } \\
\text { 2003) wearing course type IIIA }\end{array}$ & \multicolumn{2}{c|}{ RAP specification } \\
\hline Standard Sieves & English Sieves & Min. & Max. & \%passing & \%Retaining \\
\hline $19.00 \mathrm{~mm}$ & $3 / 4 "$ & --- & 100 & 100 & 0 \\
\hline $12.50 \mathrm{~mm}$ & $1 / 2 "$ & 90 & 100 & 94 & 6 \\
\hline $9.50 \mathrm{~mm}$ & $3 / 8 "$ & 76 & 90 & 84 & 10 \\
\hline $4.75 \mathrm{~mm}$ & $\# 4$ & 44 & 74 & 55 & 29 \\
\hline $2.36 \mathrm{~mm}$ & $\# 8$ & 28 & 58 & 36 & 19 \\
\hline $0.30 \mathrm{~mm}$ & $\# 50$ & 5 & 21 & 13 & 23 \\
\hline $0.075 \mathrm{~mm}$ & $\# 200$ & 4 & 10 & 5.2 & 7.8 \\
\hline Pan & --- & & & & 5.2 \\
\hline
\end{tabular}

Four percentages $(0 \%, 20 \%, 30 \%$, and $40 \%)$ of RAP were used as a percentage of the total mixture to know the effect of low and high percentages of RAP while compensating for the decrease in Asphalt binder content. Sieve analysis of RAP was performed and divided onto a No. 4 sieve prior to use in the production of Asphalt mixtures as shown in Figure 2.

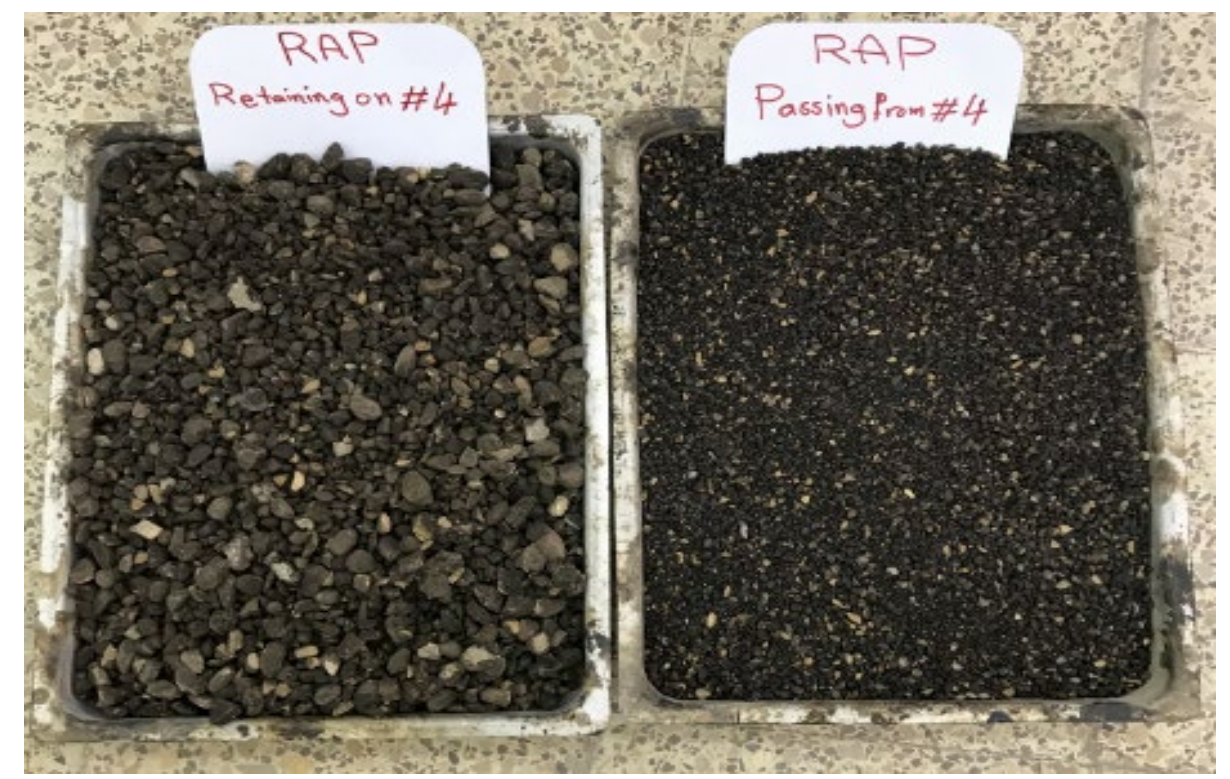

Figure 2. Sieve analysis of RAP material.

\section{MIX DESIGN}

The design of the both HMA and WMA mixes (with and without RAP) were carried out by the Marshall procedure according to the ASTM D 6926 - 10 [16] and ASTM D6927 - 15 [17]. The specimens were compacted with 75 Marshall Hammer blows applied at each side of the specimen. The production and placement temperatures of hot and warm mixes are $161{ }^{\circ} \mathrm{C}, 148{ }^{\circ} \mathrm{C}, 140{ }^{\circ} \mathrm{C}$, and $128{ }^{\circ} \mathrm{C}$, respectively depending on the relationship between the viscosity and the temperature by the rotational viscosity at temperatures of 135 ${ }^{\circ} \mathrm{C}$ and $165^{\circ} \mathrm{C}$ utilizing the Brookfield viscometer test of the binder according to ASTM D4402-15, 2015 [20].

\section{LABORATORY WORK}

\subsection{Samples Preparation}

For HMA mixtures, three specimens were prepared for each percentage $(4 \%, 4.5 \%, 5 \%, 5.5 \%, 6 \%)$ of $40 / 50$ Asphalt binder using Marshall mix design method according to (ASTM D6926-10) [16] and (ASTM D6927-10) 
[17], then determining the volumetric characteristics, Marshall stability and flow value to select the optimum Asphalt content. Asphaltic mixtures are produced and placed at Asphalt temperatures as shown in Table 6 proper to the viscosity of $170 \pm 20$ and $280 \pm 30$ centistokes, respectively (Asphalt Institute, 2015) [21].

In the same way, specimens are prepared for WMA mixtures and for each percentage of Sasobit which are (1\%, $2 \%, 3 \%$ and $4 \%$ ). All the specimens of all mixtures (HMA and WMA) were subjected to further tests (stability of Marshall and flow value, wheel track test to evaluate permanent deformation, and indirect tensile strength to evaluate moisture damage).

\subsection{Tests}

\subsubsection{Marshall Test}

Firstly, the bulk specific gravity of each specimen was performed according to ASTM D2726-17 [22] and the maximum theoretical specific gravity was determined according to ASTM D 2041- 11 [23]. Moreover, the percentages of air void were calculated according to ASTM D3203-05 [24]. Secondly, the Marshall stability and flow measurements were performed for each sample by ASTM D6927-10 [17] in order to find the optimum Asphalt content. the optimum Asphalt binder is (5.0 percent) which is obtained from the average Asphalt binder content of highest stability, highest unit weight, and 4\% air voids from results exhibited in Table 6. Finally, use the obtained optimal content of the Asphalt binder to prepare new Marshall Specimens and subject them to the tests. Figure 3 exhibited the Marshall stability and flow test.

Table 6. Volumetric Properties of HMA with Different Asphalt Contents.

\begin{tabular}{|c|c|c|c|c|c|}
\hline $\begin{array}{c}\text { Binder } \\
\begin{array}{c}\text { Content } \\
\%\end{array}\end{array}$ & stability (kN) & Flow (mm) & $\begin{array}{c}\text { Unit Weight } \\
\left(\mathbf{g m} / \mathbf{c m}^{\mathbf{3}}\right)\end{array}$ & $\begin{array}{c}\text { Air Voids } \\
\mathbf{\%}\end{array}$ & $\begin{array}{c}\text { V.F.A } \\
\text { \% }\end{array}$ \\
\hline 4.0 & 9.24 & 1.8 & 2.268 & 7.372 & 50.102 \\
\hline 4.5 & 9.93 & 2.5 & 2.289 & 6.062 & 58.341 \\
\hline 5.0 & 10.92 & 2.8 & 2.317 & 4.201 & 70.230 \\
\hline 5.5 & 10.33 & 3.2 & 2.310 & 3.228 & 77.354 \\
\hline 6.0 & 8.40 & 3.9 & 2.299 & 2.554 & 87.699 \\
\hline
\end{tabular}
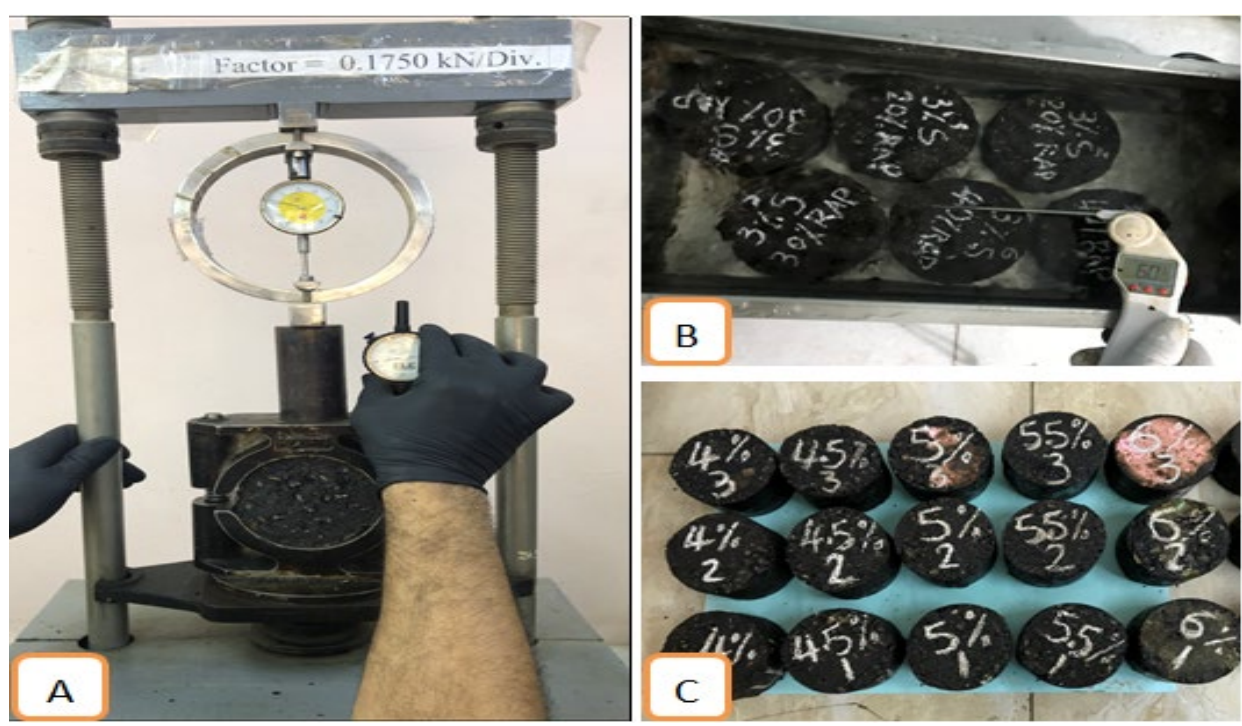

Figure 3. Marshall stability testing apparatus (A) Marshall stability and flow apparatus, (B) water path $60^{\circ} \mathrm{C},(\mathrm{C})$ Marshall specimens. 


\subsubsection{Moisture Susceptibility}

An indirect tensile strength testing by ASTM D6931-12, 2007 [25] that was carried out on both types of HMA and WMA samples to find the moisture sensitivity of these mixtures. For this test, the samples were prepared and compacted utilizing the Marshall mix design procedure, Marshall hammer to an air voids level of $7 \% \pm 1 \%$. The subsets of three samples were prepared at normal condition (dry) and another subset of three specimens was prepared after moisture conditioning (wet). The moisture conditioning (wet) samples were exposed to a vacuum to obtain of 55-80\% saturation of the samples. Subsequently, the samples were soaked in the water path at $60^{\circ} \mathrm{C} \pm 1^{\circ} \mathrm{C}$ for $24 \mathrm{~h}$, and then placed in a water bath at $25^{\circ} \mathrm{C} \pm 1^{\circ} \mathrm{C}$ for 1 hour. The dry samples were placed in a water bath at $25^{\circ} \mathrm{C}$ for $20 \mathrm{~min}$. All specimens (dry and wet) were then tested in indirect tensile testing (IDT) at $25^{\circ} \mathrm{C}$, and then determining the forces required to break the samples. The tensile strength ratio (TSR) was calculated based on the ratio of conditional to unconditional IDT. The minimum requirement of TSR value is $80 \%$ according to ASTM D4867M-09 [26].

Although, the tensile strength of Asphalt pavement is not significantly strong as its compression, the tensile strength is still important in various pavement applications. Pavement engineers are interested in the tensile characteristics of the Asphalt mixture because of the regarded cracks problems. The tensile properties are determined by the indirect tensile strength test (IDT) which additionally related the cracking characteristics of the pavements as studied by a group of researchers [27]. The higher tensile strength, the strong cracking resistance is obtained. Indirect tensile strength (IDT) test was carried out to all samples by applying constant loading rate of $5 \mathrm{~cm} / \mathrm{min}$ at $25^{\circ} \mathrm{C}$ along with the middle point of $12.70 \pm 0.3 \mathrm{~mm}$ span until the samples fail due to from vertical deformation. The maximum load recorded for determining tensile strength as in Equation (1).

$$
\mathrm{St}=\frac{2000 P}{\pi D t}
$$

Where, St: Tensile strength $(\mathrm{kPa}), \mathrm{P}$ : Maximum load $(\mathrm{N}), \mathrm{T}$ : height of sample $(\mathrm{mm})$, and D: diameter of the sample (mm).

The TSR (tensile strength ratio) is a ratio between the indirect tensile strength of the wet (conditional) specimen and that of the dry (unconditional) specimen. The TSR value was calculated for all mixes as in Equation (2). Typically, TSR value should be greater than or equal to $80 \%$ which is acceptable resistance to moisture damage. Figure 4 shows some of the samples prepared and tested.

$$
\mathrm{TSR}=\left(\frac{S t m}{S t d}\right) 100 \%
$$

Where, TSR: Tensile strength ratio (\%), Stm: average tensile strength of the moisture-conditioned (wet) subset $(\mathrm{kPa})$, and Std: average tensile strength of the dry subset $(\mathrm{kPa})$.
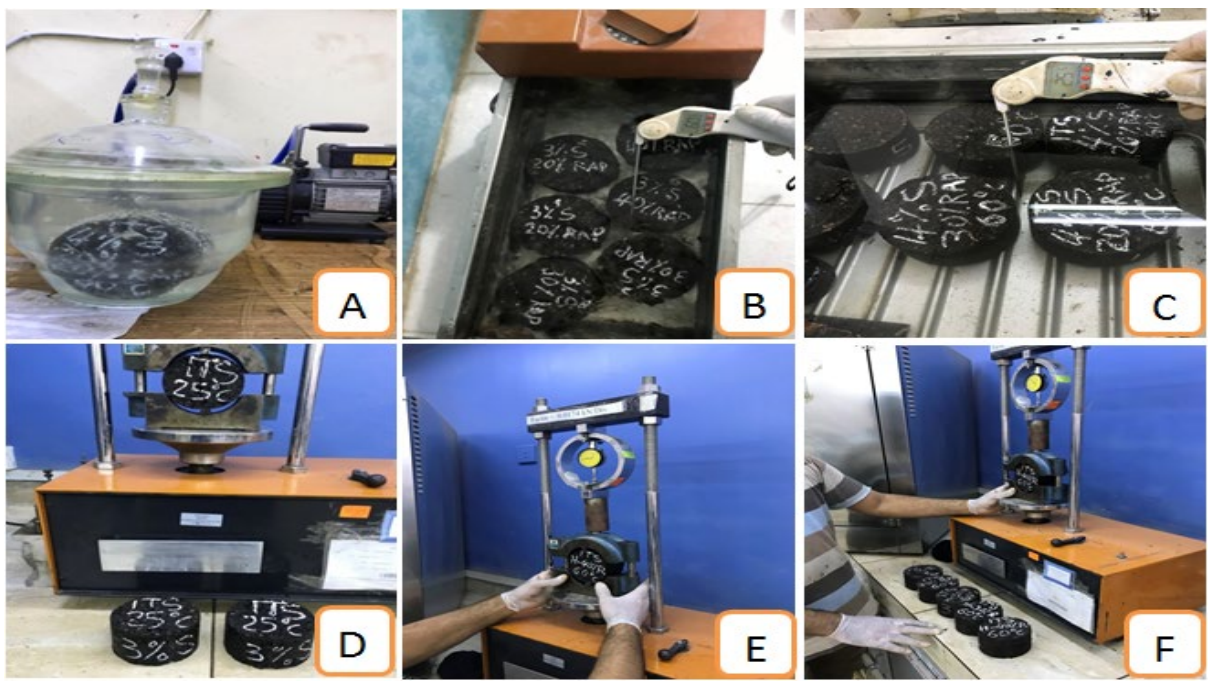

Figure 4. Indirect Tensile Strength Test (A) vacuum of specimen, (B) water bath at $60^{\circ} \mathrm{C},(\mathrm{C})$ water bath at $60^{\circ} \mathrm{C},(\mathrm{D})$ unconditioned specimens test, $(\mathrm{E}, \mathrm{F})$ conditioned specimens' test. 


\section{TEST RESULTS AND DISCUSSION}

\subsection{Marshall Stability}

The relation among the Marshall stability and flow value with the different content of RAP-for both HMA and WMA mixtures-as shown in Figures 5 and 6, respectively.

For comparing the WMA mixture with the HMA mixture after adding different rates of reclaimed Asphalt pavement, as seen in these Figures, the Marshall stability of HMA increases with the increase in RAP percentage until it reached to $30 \%$ RAP, then the value decreased for $(40 \%)$ RAP, which was greater than control mix by (24\%). Moreover, the Marshall Flow was less than the control mix by (34\%) for this percentage.

For the WMA mixtures, the value of Marshall stability was $(12.7 \mathrm{kN})$ for $(0 \%) \mathrm{RAP}$, and then slight decrease to $(11.7 \mathrm{kN})$ for $(20 \%)$ RAP. This was followed by increased slightly to $(14.0 \mathrm{kN})$ for $(40 \%)$ RAP, which was greater than the control warm mix ( $0 \%$ RAP) by $(9.3 \%)$, while the Marshall flow was less than the control warm mix by (46.7\%). The highest values of Marshall stability for HMA and WMA mixtures are shown in (30\%) and (40\%) RAP respectively. Moreover the highest value of Marshall flow appeared in $(0 \%)$ for both the HMA and WMA mixtures. The increase in the Marshall stability is attributed to the presence of the RAP aged binder in the HMA and WMA mixtures and crystal wax structure of Sasobit in the WMA which may cause a stiffening effect.

Generally, all mixtures (warm and hot) exceed the minimum limit of Marshall stability, which was (8.0 kN), but the flow value was less than minimum limit which was $(2.0-4.0) \mathrm{mm}$ recommended by (S.C.R.B. R/9, 2003) [15] for the surface layer. This can be due to the high stiffness and low air voids of mixes due to the addition of reclaimed Asphalt pavement and this improving the Marshalls stability and flow values in general. This leads to improved resistance of the mixtures to rutting.

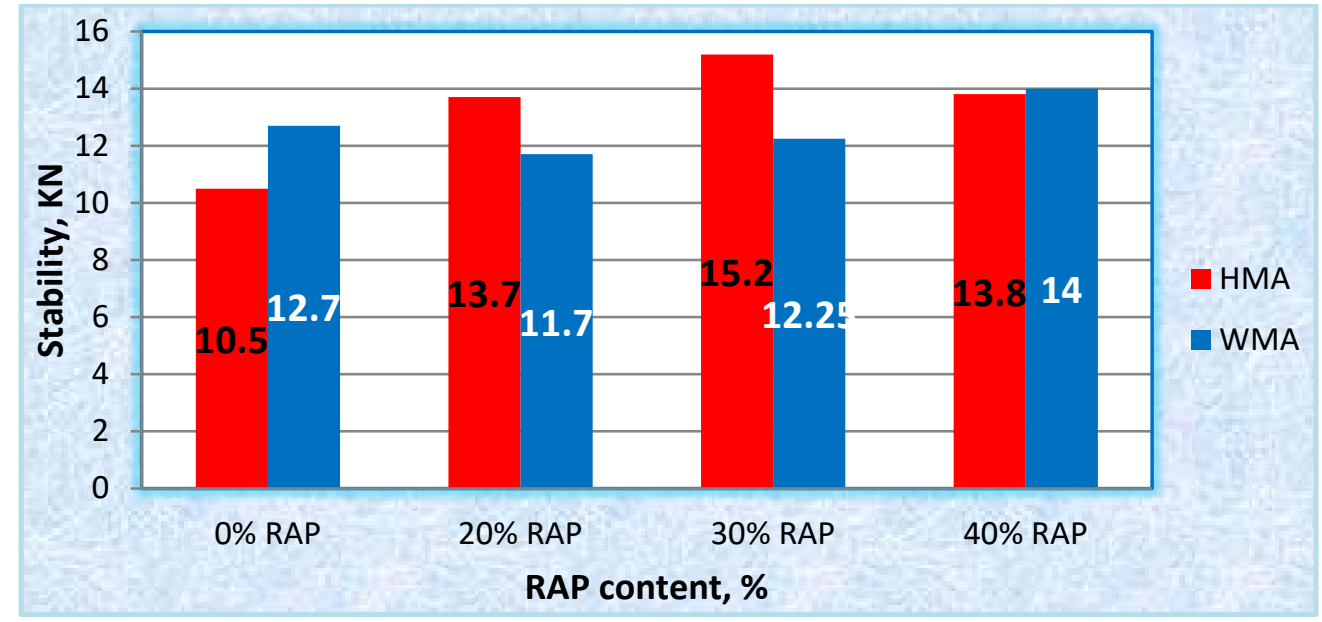

Figure 5. Effect of RAP percentage on Marshall Stability for HMA and WMA

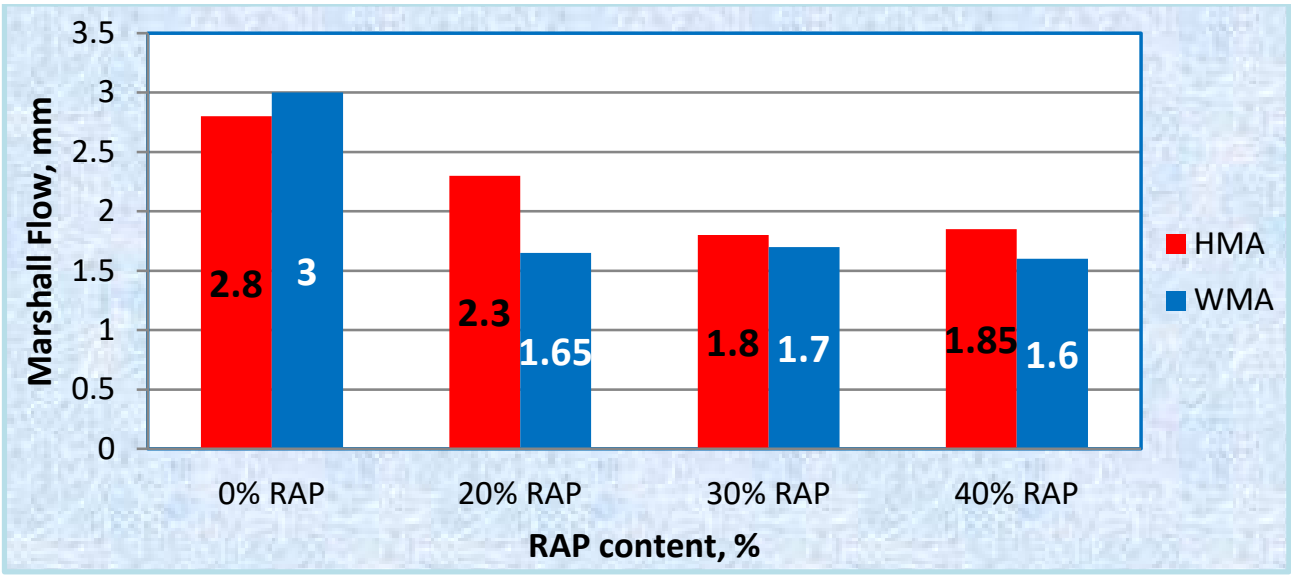

Figure 6. Effect of RAP percentage on Marshall Flow for HMA and WMA. 


\subsection{Moisture Susceptibility}

Figures 7 and 8 show the relationships between the RAP content and the indirect tensile strength of both hot and warm mixes for unconditioned (dry) and conditioned (wet) samples, respectively. As seen in these Figures, for the HMA-RAP mixes, the indirect tensile strength (IDT) values for dry and wet conditions are decreased than that of the original mixtures when $20 \%$ RAP was added, and then slightly increased relative to the other percentages. The highest IDT value was for control HMA, while the lowest value was for the WMA-20\% RAP. All the IDT values of HMA-RAP mixes for different percentages are less than the control HMA. For the WMARAP mixes, the IDT values for dry condition are decreased with the $20 \%$ RAP than the control WMA, and then slightly increase with the other percentage of RAP. The IDT values for wet condition are decreased with the increase in RAP content until reach to $30 \%$ RAP, and then the values have increased with $40 \%$ RAP. The maximum and minimum IDT values were for control WMA (0\% RAP) and WMA-30\% RAP, respectively. Generally, the IDT values of hot and warm mixes with RAP for all percentage are less than that of hot and warm mixes without RAP because the addition of RAP led to an increase the air voids of the mixes also the aged binder in RAP, which made the mixtures are more sensitive to moisture.

As for the tensile strength ratio shown in Figure 9, it can be seen the relationship between RAP content and TSR for both HMA and WMA mixtures. For HMA mixtures, the TSR was (92\%) for origin mix and then decrease with an increase in RAP percentage to $88 \%, 86 \%$, and $85 \%$ for $20 \%, 30 \%$, and $40 \%$ RAP, respectively. and this applies to the warm mixes, where it was $87 \%, 86 \%, 84 \%$, and $83 \%$ for control WMA( $0 \%$ RAP), $20 \%, 30 \%$, and $40 \%$ RAP respectively. This was in agreement with the researcher [28].

The TSR of the warm mixes were less than the hot mixes for all percentages of RAP because the lower mixing and compaction temperature of WMA mixtures lead to incomplete dry of the aggregate. All the mixtures were exceeding the minimum limit (80\%) of the Tensile Strength Ratio (TSR), which was recommended by ASTM D4867M-09, 2014 [26]. The WMA without RAP performed better in terms of moisture susceptibility, and this is an agreement with the opinion of the researcher [29].

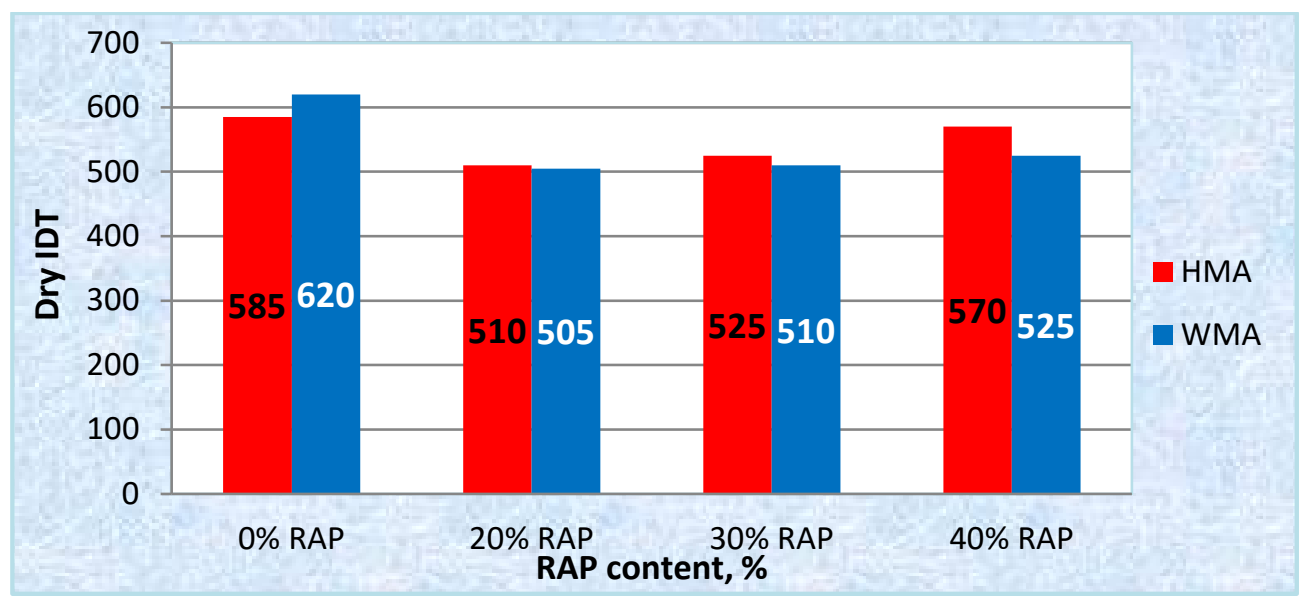

Figure 7. Impact of RAP percentage on Indirect Tensile Strength (dry condition).

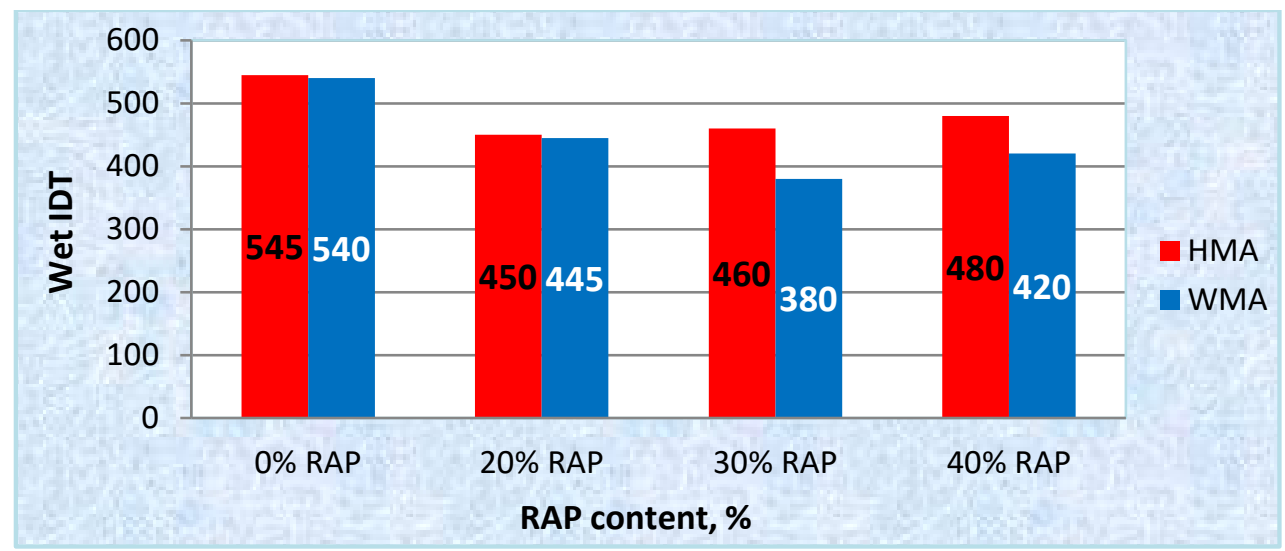

Figure 8. Effect of RAP percentage on Indirect Tensile Strength (wet condition). 


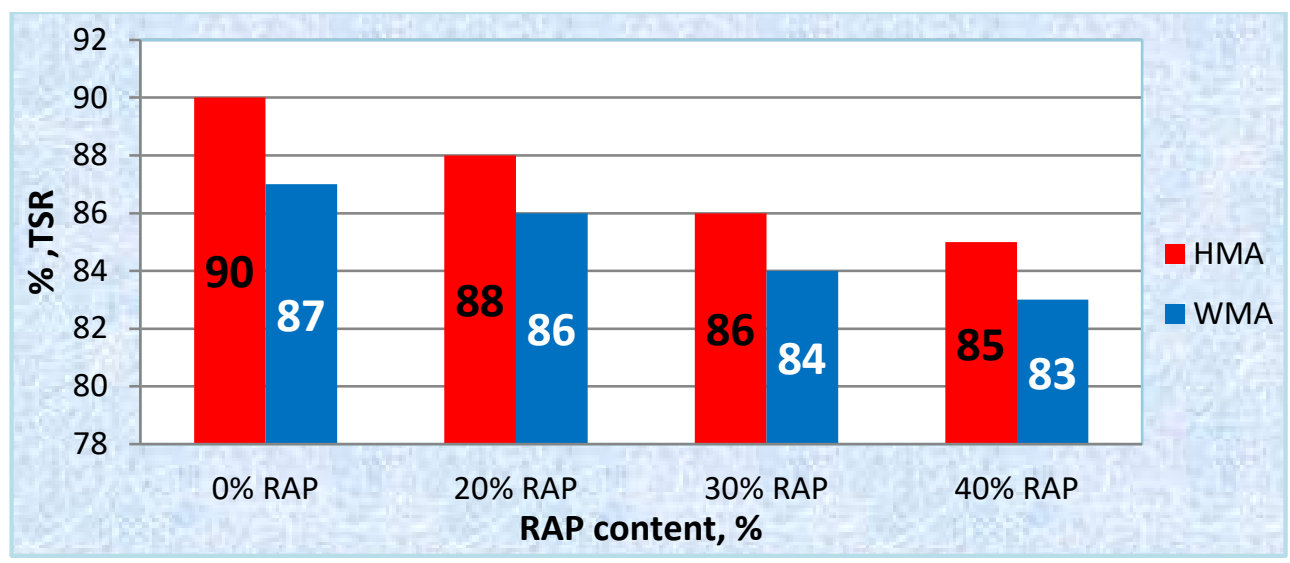

Figure 9. Effect of RAP percentage on Tensile Strength Ratio.

\section{CONCLUSIONS AND RECOMMENDATIONS}

\subsection{Conclusions}

1. The addition of RAP to the mixture up to $40 \%$ significantly increased Marshall stability and reduced the flow of both HMA and WMA mixtures which lead to raising the potential resistance to rutting.

2. The addition of RAP to mixtures was shown to increase their sensitivity to moisture, but the sensitivity of RAP mixtures to damage caused by moisture was not a concern with the mixtures tested in this research, have all mixtures had a TSR exceeding $83 \%$. However, the TSR value of the mixtures without RAP generally higher than that of RAP mixtures. Additionally, no index of obvious stripping was found in any sample.

3. Sasobit modified Asphalt binder can improve workability at lower mixing temperature for WMA with or without RAP as observed during mixing, and that all mixtures were workable, easy to compact and lower emissions during the production.

4. Sasobit not only decreases the construction temperatures of Asphalt mixtures, it is also possible to manufacture Asphalt mixtures that contain high RAP percentages using Sasobit.

5. Overall, WMA mixtures prepared with Sasobit used in this study perform better than HMA mixtures in terms of rutting characteristics. Beside modification effects of WMA additives, the lower amount of aging due to lower production temperatures of the warm additive plays an important role in the total assessment of these innovative technologies.

\subsection{Recommendations}

1. To completely understood the possibilities and disadvantages of the usage of Asphaltic mixtures made with high RAP content, field experiments should have constructed using HMA and WMA mixtures containing high RAP content. These tests should be carefully designed (mixing and paving) and supervised through and after construction.

2. The possibility for using high RAP material within a pavement at strategic locations should be considered, but not as a surface layer as it can be used as a binder layer below the surface layer which should have high specifications and good material quality.

3. The moisture-induced damage potential is the most important concern associated with the WMA mixes. However, this issue can be mitigated by using effective anti-moisture or anti-stripping agents (e.g., hydrated lime).

\section{REFERENCES}

1 Kasozi, Andrew M (2010). Properties of Warm Mix Asphalt from Two Field Projects: Reno, Nevada and Manitoba, Canada..

2 Gandhi, T. (2008). Effects of Warm Asphalt Additives on Asphalt Binder and Mixture Properties, Clemson Univ., PhD.Dissertation.

3 W. Rogers, (2011).Influence of warm mix additives upon high RAP Asphalt mixes, Clemson Univ., PhD.Dissertation. 
4 Alossta, A. (2011). Evaluation of Warm Mix Asphalt Versus Conventional Hot Mix Asphalt for Field and Laboratory-Compacted Specimens. Master thesis, Arizona State University.

5 Arshad, A. K., Kridan, F. A. M., \& Rahman, M. Y. A. (2013). The effects of Sasobit ${ }^{\circledR}$ modifier on binder at high and intermediate temperatures. International Journal of Engineering and Advanced Technology (IJEAT), 2(3):81-84.

6 O. Kristjansdottir, (2006). Warm Mix Asphalt for Cold Weather Paving," Master thesis, University of Washington.

7 Kristjánsdóttir, Ó., Muench, S. T., Michael, L., \& Burke, G. (2007). Assessing potential for warm-mix asphalt technology adoption. Transportation Research Record, 2040(1), 91-99.

8 M. Mejías-santiago, J. D. Doyle, I. L. Howard, and E. R. Brown, (2012). Evaluation of Warm-Mix Asphalt Technologies for Use on Airfield Pavements Geotechnical and Structures Laboratory.

9 Martinho, F., Capitão, S., \& Picado-Santos, L. (2012). Sustainable pavements: warm asphalt mixtures made with recycled aggregates from different industrial by-products. In Atas do EPAM4-4th European Pavement and Asset Management Conference, Malmö, Suécia.

10 Fakhri, M., \& Azami, A. (2017). Evaluation of warm mix asphalt mixtures containing reclaimed asphalt pavement and crumb rubber. Journal of Cleaner Production, 165: 1125-1132.

11 D. Singh, S. F. Chitragar, and P. K. Ashish, (2017). Comparison of moisture and fracture damage resistance of hot and warm Asphalt mixes containing reclaimed pavement materials. Constr. Build. Mater., 157:1145-1153, doi: 10.1016/j.conbuildmat.2017.09.176.

12 M. J. Ayazi, A. Moniri, and P. Barghabany, (2017). Moisture susceptibility of warm mixed-reclaimed Asphalt pavement containing Sasobit and Zycotherm additives. Pet. Sci. Technol., 35 (9): 890-895, doi: 10.1080/10916466.2017.1290655.

13 A. K. Arshad, F. A. M. Kridan, N. A. Kamaluddin, and E. Shafie, (2015). Evaluation of warm mix Asphalt performance with high RAP content. J. Teknol., 73 (4): 51-54, doi: 10.11113/jt.v73.4287.

14 S. Zhao, B. Huang, X. Shu, and M. Woods, (2013). Comparative evaluation of warm mix Asphalt containing high percentages of reclaimed Asphalt pavement. Constr. Build. Mater., 44: 92-100, doi: 10.1016/j.conbuildmat.2013.03.010.

15 R. E. SCRB, (2003). Standard Specifications for Roads and Bridges." Section R/9, Hot-Mix Asphaltic Concrete Pavement.

16 ASTM D6926 - 10. (2010). Standard practice for preparation of bituminous specimens using Marshall apparatus, ASTM.

17 ASTM D6927 - 15, (2015). Standard Test Method for Marshall Stability and Flow of Asphalt Mixtures 1. i:1-7, doi: 10.1520/D6927-15.2.

18 SASOL Performance Chemicals. https://www.sasol.com. Accessed on 04-October-2020.

19 ASTM D6307 - 10, (1999). Asphalt Content of Hot-Mix Asphalt by Ignition Method 1. 04: 6-10, doi: 10.1520/D6307-10.2.

20 ASTM, D. (2015). Standard test method for viscosity determination of asphalt at elevated temperatures using a rotational viscometer. In American Society for Testing and Materials.

21 Asphalt Institute, Asphalt Mix Design Methods (Metodos de Diseño de Concreto Asfaltico). 2015.

22 ASTM D2726-17, (2017). Standard test method for bulk specific gravity and density of non-absorptive compacted Asphalt mixtures, ASTM.

23 ASTM D2041-11, (2011). Standard test method for theoretical maximum specific gravity and density of bituminous paving mixtures, $A S T M$.

24 ASTM D3203-05, (2005). Standard test method for percent air voids in compacted dense and open bituminous paving mixtures, $A S T M$.

25 ASTM D6931-12, (2007). Standard Test Method for Indirect Tensile ( IDT ) Strength of Bituminous Mixtures. ASTM Int., no. Fixed desination D6981, pp. 1-5, doi: 10.1520/D6931-12.2.

26 ASTM D4867M-09, (2014). Standard Test Method for Effect of Moisture on Asphalt Concrete Paving Mixtures. ASTM, No. of pages: 5.

27 Charoentham, N., \& Macharoen, P. (2017). A Study of Moisture Damage in Warm Mix Asphalt Concrete with Reclaimed Asphalt Pavement. Journal of the Eastern Asia Society for Transportation Studies, 12: 1458-1476.

28 F. Moghadas Nejad, A. Azarhoosh, G. H. Hamedi, and H. Roshani, (2014). Rutting performance prediction of warm mix Asphalt containing reclaimed Asphalt pavements. Road Mater. Pavement Des. 15 (1): 207219, 2014, doi: 10.1080/14680629.2013.868820.

29 N. Guo, Z. You, Y. Zhao, Y. Tan, and A. Diab, (2014). Laboratory performance of warm mix Asphalt containing recycled Asphalt mixtures," Constr. Build. Mater., vol. 64:141-149, doi: 10.1016/j.conbuildmat.2014.04.002. 